\title{
Expression of galectin-3 in nephrotic syndrome glomerulopaties in children
}

\author{
Danuta Ostalska-Nowicka1, Michal Nowicki², Beata Kondraciuk², \\ Malgorzata Partyka ${ }^{2}$, Dariusz Samulak ${ }^{3}$, and Martin Witt ${ }^{4}$
}

Departments of ${ }^{1}$ Paediatric Cardiology and Nephrology, ${ }^{2}$ Histology and Embryology, ${ }^{3}$ Surgical Gynaecology Poznan University of Medical Sciences, Poland,

${ }^{4}$ Anatomy Department, Technical University in Dresden, Germany

\begin{abstract}
Background: Galectins are a family of ancient animal carbohydrate binding proteins; the name is from their description as $\beta$-galactoside-specific lectins. They have been strongly implicated in inflammation and cancer. Studies of the association of galectins with various aspects of kidney disease in humans are still at an early stage. In line with the above, the aim of the present report was to analyse the immunohistochemical expression of galectin-3 (the only chimera galectin currently identified) in renal biopsy specimens of children with idiopathic nephrotic syndrome (INS). Patients and Methods: Eighteen children with minimal change disease (MCD), 30 with diffuse mesangial proliferation (DMP) and 11 with focal segmental glomerulosclerosis (FSGS) treated between 2003 and 2006 in the Department of Paediatric Cardiology and Nephrology, Poznan University of Medical Sciences. An indirect immunohistochemical protocol using a polyclonal rabbit antibody against human galectin-3 was employed. Results: In the control, MCD and DMP children who responded to steroid therapy anti-galectin-3 reactivity was present both in renal cortex and medulla. It was the strongest within cortical collecting ducts and subjectively less expressed in distal tubules. The total number of galectin3 positive cortical and medullary segments of collecting ducts was significantly higher in the subjects who did not respond to steroid therapy These patients revealed also immunohistochemical reactivity of galectin-3 within nuclei of individual glomerular mesangial cells $(\mathrm{p}<0,001)$. Conclusions: A suggested galectin-3 authority in mature human glomeruli during proteinuric glomerulopathies may indicate, on the one hand, its anti-inflammatory effect, but on the other can prognosticate a further glomerular reconstruction leading to FSGS. Taken together, both glomerular and extraglomerular galectin-3 immunoreactivity in certain DMP individuals could be regarded as the factor of unfavourable prognosis.
\end{abstract}

Key words: galectin-3, glomerulopathy, tubulopathy, immunohistochemistry, children

\section{Introduction}

Galectins are a family of ancient animal carbohydrate binding proteins; the name is from their description as $\beta$-galactoside-specific lectins. They have been strongly implicated in inflammation and cancer and may be useful as targets for the development of new anti-inflammatory and anti-cancer therapies (reviewed in [1]).

Galectins are present at high concentration in a limited range of cell types, different for each galectin. They bind to sugar molecules on the surface of cells. All galectins bind lactose and other $\beta$ galactosides, but

Correspondence: M Nowicki, Dept. of Histology and Embryology, Poznan University of Medical Sciences, ul. Swiecickiego 6, 60 - 781 Poznan, Poland, tel. +48 618546 446, fax. +48 618546 440, e-mail: mnowicki@amp.edu.pl they differ in their affinity for more complex saccharides [2]. The galectins are defined by their structural similarities in their carbohydrate recognition domains (CRD) and by their affinity for $\beta$-galactosides. They have been classified into three classes, prototype, chimera, and tandem-repeat galectins (reviewed in [1]).

The only chimera galectin currently identified is galectin-3 which contains one CRD connected to a non-lectin domain; in addition to the CRD it contains a prolineand glycine-rich N-terminal domain (ND) through which is able to form oligomers [3-5]. Galectin-3 is also called Mac-2, L29, CBP35 or \&BP, and is expressed in tumour cells (reviewed in [6]), macrophages [7], activated $\mathrm{T}$ cells [8], certain epithelial cells [9] and fibroblasts [10]. It binds a variety of matrix glycoproteins including laminin and 
fibronectin [11]. Intracellularly, galectin-3 acts to prevent apoptosis [reviewed in [1]). Depending on the cell type, galectin-3 can be localized in the extracellular matrix, the cell surface, in the cytoplasm, or in the nucleus (reviewed in [1]). Galectin-3 has been shown to exhibit pro-inflammatory activities in vitro and in vivo; it induces pro-inflammatory and inhibits Th2 type cytokine production (reviewed in [1]). High levels of circulating galectin-3 have been shown to correlate with the malignancy potential of several types of cancer. Galectin-3 is known to play a role in tumour growth, metastasis, and cell-to-cell adhesion (reviewd in [6]). It also serves as a preferred substrate for matrix metalloproteinase-9 [12]. Finally, human and mouse galectin-3 share approximately $80 \%$ homology in their amino acid sequence [13].

The expression of galectin-3 is well known in animal urinary systems. In a normal rat kidney, it is expressed in epithelial cells of distal tubules [14,15]. Interestingly, in a rat model of acute mesangial proliferative glomerulonephritis [14], galectin-3 expression was found increased in distal tubules, as well as in glomerular macrophages, mesangial cells and proximal tubules. The similar pattern, except of mesangium and glomerular macrophages was observed in a ischaemia/reperfusion renal failure model in rats. Galectin-3 expression increased in proximal and distal tubuli at $2-48 \mathrm{~h}$ after reperfusion and was then followed by a normalization of the increased expression [15]. Therefore, those findings were considered to be acute reactions. On the other hand, in the study of streptozotocin-induced rat diabetes, galectin-3 expression in glomeruli was observed at 2 months after injury [16]. In the murine urinary system galectin-3 was expressed continuously from the kidney to the distal end of the urethra. The renal cortex expressed galectin3 more intensely than the medulla. Renal galectin-3 immunoreactivity was strongest in the cortical collecting ducts, where principal cells were the sole cellular source.

Studies of the association of galectins with various aspects of kidney disease in humans are still at an early stage [17-20]. In children with primary glomerulonephritis, proteinuria is an important risk factor for the progression of glomerular disease and follows both qualitative and quantitative alterations in podocytes and the glomerular architecture [21]. The concept that podocytes, rather than mesangial cells, are the major culprit in the progression of glomerular diseases is gaining ground. In patients with nephrotic syndrome (NS), proteinuria (> $50 \mathrm{mg} / \mathrm{kg}$ per $24 \mathrm{~h}$ ) and progressive loss of renal function are often mixed with tubular proteinuria superimposed on the underlying glomerular pattern [22]. This is most typical of focal segmental glomerulosclerosis (FSGS) with intensive proteinuria, progressive type [23]. The pathogenesis of the NS has an immunological basis and might be due to the presence of a circulating factor. This is entirely compatible with an immunological hypothesis, in that the factor(s) might be produced by cells of the immune system, either as the result of immunological reaction to antigen exposure or due to a primary abnormality of the immune system itself [24].

The aim of this study was to analyse the immunohistochemical expression of galectin-3 in renal biopsy specimens of children with idiopathic (primary) glomerulopathies.

\section{Patients and Methods}

Patients. The study group was composed of children with idiopathic nephrotic syndrome (INS), who were treated between 2003 and 2006 in the Department of Paediatric Cardiology and Nephrology, Poznan University of Medical Sciences. Two hundred and eighty-six children were referred to our clinic and evidence of proteinuria was found in 146 of them. Eighty-four patients (44 boys and 40 girls), following International Study for Kidney Diseases in Children recommendations, underwent a biopsy [25]. The indications included: primary idiopathic glomerulonephritis $(n=36)$, steroid-resistant nephrotic syndrome (SRNS) $(n=23)$ and secondary glomerulonephritis $(n=25$, who were excluded from further analysis). According to World Health Organization definitions $[25,26]$, histological evaluation of the study group revealed: minimal change disease (MCD), $n=18$; diffuse mesangial proliferation (DMP), $n=30$; and FSGS, $n=11$. DMP diagnosis was based on the number of cells per mesangial area (four and more). INS was classically characterized by the absence of significant deposits by immunofluorescence microscopy (IF), except for FSGS and/or hyalinosis of FSGS, which bound IgM and C3 antiserum. There was no significant difference between the various categories defined by IF [26]. In 25 patients with DMP the presence of IgM and/or IgG within the mesangial area was observed without electron-dense deposits. No IgA nephropathy was diagnosed in the subjects. The relevant data are presented in Table 1.

The Ethics Committee of Poznan University of Medical Sciences approved the research protocol and the parents of all study participants gave informed consent for the investigation. Kidney biopsy specimens were fixed in Bouin's solution for $24 \mathrm{~h}$ and subsequently embedded in paraffin.

Controls. Ten age- and sex-matched children in whom total nephrectomy due to the presence of Wilms tumour had been performed served as a control group. All of these subjects had normal renal function. Macroscopically normal-appearing kidney tissue was fixed in Bouin's solution and saved for the subsequent procedure.

Antibodies and immunohistochemistry. For light microscopy, 6 $\mu \mathrm{m}$ thick sections were dewaxed and processed according to the indirect avidin-biotin-peroxidase technique [27]. A polyclonal rabbit antibody against human galectin-3 (diluted 1:100; Santa Cruz Biotechnology, sc-20157, Heidelberg, Germany) and monoclonal mouse anti-CD68 (diluted 1:100; Santa Cruz Biotechnology, sc70761, Heidelberg, Germany) were employed. Endogenous peroxidase reaction was abolished by pre-treatment of the sections with $0.3 \% \mathrm{H}_{2} \mathrm{O}_{2}$ in phosphate-buffered saline (PBS) prior to incubation with the antibodies. Following initial incubation with the primary antibody for $24 \mathrm{~h}$ at $4{ }^{\circ} \mathrm{C}$, sections were respectively incubated for $1 \mathrm{~h}$ at room temperature with goat anti-rabbit IgG (diluted 1:300; Sigma, Deisenhofen, Germany), goat anti-mouse IgG (diluted 1:300; Santa Cruz Biotechnology, sc-2072, Heidelberg, Germany) 
Table 1. Clinical and biochemical characteristics of the study population at the time of kidney biopsy.

\begin{tabular}{|lcccc|}
\hline \multirow{2}{*}{ Characteristics } & \multicolumn{4}{c|}{ Study group } \\
\cline { 2 - 5 } & $\mathrm{MCD}$ & DMP-s & DMP-r & lisGS \\
\hline Number of paticnts & 18 & 18 & 12 & 11 \\
\hline Agc, ycars & $10,7(6-18)$ & $10(5-16)$ & $10(5-14)$ & $11,5(6-16)$ \\
\hline Scx, malc/[cmalc & $10 / 8$ & $8 / 10$ & $8 / 4$ & $6 / 5$ \\
\hline Protcinuria, $\mathrm{mg} / \mathrm{kg} / 24 \mathrm{~h}$ & $41(5-85)$ & $30(10-60)$ & $90(73-99)^{*}$ & $56(37-68)^{*}$ \\
\hline Lrythrocyluria, number of paticnts & 4 & 9 & 4 & 8 \\
\hline GFR, ml/min $/ 1,73 \mathrm{~m}^{2}$ & $98 \pm 8$ & $105 \pm 11$ & $108 \pm 15$ & $85 \pm 12^{*}$ \\
\hline Scrum albumin, g/dl & $2,8 \pm 0,8$ & $3,1 \pm 0,8$ & $2,5 \pm 0,3^{*}$ & $2,2 \pm 0,5^{*}$ \\
\hline Median galectin-3 expression in \% per glomerular area & 0 & 0 & $1,866^{*}$ & $1,745^{*}$ \\
\hline Mean percentage of involved glomeruli & 0 & 0 & $90^{*}$ & 15 \\
\hline
\end{tabular}

and then incubated with a streptavidin-biotin-peroxidase reagent (Vectastain Elite; Vector Laboratories, Burlingame, CA, USA) for $45 \mathrm{~min}$ at room temperature. The activity of peroxidase was visualized using $0.5 \% 3,3^{\prime}$-diaminobenzidine (DAB) in Tris- $\mathrm{HCl}(\mathrm{pH}$ 7.6) containing $0.3 \% \mathrm{H}_{2} \mathrm{O}_{2}$. In all the control samples, the primary antibody was replaced by a non-immune serum or PBS. Photomicrographs were taken using a charge-coupled device (CCD) camera connected to a Nikon Digital Sight S-U1 unit, and the images were labelled and assembled as plates using Adobe Photoshop 7.0.

Double immunofluorescence. Some sections were doublelabelled to confirm the identity of cells that were positive or negative for galectin-3 in the renal corpuscles. For this reason, a double immunofluorescence protocol was performed. Paraffin sections were dewaxed and incubated with mouse monoclonal antigalectin-3 antibodies (diluted 1:10; Santa Cruz Biotechnology, sc32790 , Heidelberg, Germany) at $4^{\circ} \mathrm{C}$ overnight, followed by goat anti-mouse Alexa Flour 555 secondary antibody (1:200; Molecular Probes, MobiTec, Goettingen, Germany) at $37^{\circ} \mathrm{C}$ for $1 \mathrm{~h}$. Subsequently, the sections were incubated with polyclonal rabbit antipodocalyxin antibodies (1:600; a kind gift from Dr M. G. Farquhar, San Diego, CA, USA) at $37^{\circ} \mathrm{C}$ for $1 \mathrm{~h}$, followed by incubation with Alexa Flour 488 goat anti-rabbit secondary antibody (1:200; Molecular Probes, MobiTec, Goettingen, Germany) for $30 \mathrm{~min}$ at $37^{\circ} \mathrm{C}$, The sections were then mounted in buffered glyceringelatin. These were observed with an Olympus BX60 microscope. Pictures were taken using a CCD camera connected to Analysis Soft-Imaging System (Muenster, Germany).

Quantitative and statistical analysis. Due to the limited material provided by the clinical biopsies, we were not able to assess all serial sections of individual glomeruli. Instead, we measured the area of immunoreactive cells within a colour spectrum specific for the DAB staining and determined the value of at least five glomeruli in four subsequent sections as a percentage of the whole glomerular area. Based on the morphological heterogeneity of glomeruli, which displayed various stages of the respective pathological lesions, we analysed all available glomeruli which met either DMP or FSGS criteria (Table 1). Variations in antigen distribution within renal glomeruli were evaluated using Micro Image v.4.0 software (Olympus, MS Windows XP), measuring the area of marker expression on each colour image by using the 'eye-dropper' tool for each group of patients. Estimates of galectin-3 expression were subjected to mathematical analysis in order to examine changes of these markers in certain glomerulopathies. Differences between groups were then evaluated by one-way analysis of variance test (ANOVA). To determine the significance of between group means in the analysis of variance, the nearest significant difference test (Tukey test) was used as the multiple comparison analysis. Significance was set at $p<0.05$ [28]. Finally, the analysis was performed blind on coded samples.

\section{Results}

\section{Clinical course}

As regarded to the clinical course of nephrotic syndrome, there was no correlation between galectin-3 expression and age or sex. There were, however, significant differences in galectin-3 tissue localization between patients with proteinuria who did and did not respond to steroid therapy. In the former group, consisting of all MCD and DMP patients sensitive to steroids (DMP-s), galectin-3 was expressed within individual cortical collecting ducts and distal tubules as well as thin and thick limbs of loop of Henle and medullary collecting ducts. It was not present within renal corpuscles. The latter group of children, consisting of 12 DMP patients resistant to steroids (DMP-r) and all the FSGS children who developed an unfavourable clinical course of INS, revealed immunohistochemical expression of galectin-3 within all the mentioned above structures and, additionally, glomeruli $(p<0.001)$. Detailed information is presented in Table 1.

\section{Bright field microscopy}

In the control and MCD children (Fig. 1a), antigalectin-3 reactivity was present both in renal cortex and medulla. Within the cortical region it was the strongest within cortical collecting ducts and subjectively less expressed in distal tubules (Fig. 1b). Its expression was found within cell cytoplasm and nuclei of numerous, but not all, epithelial cells. The lining of proximal convoluted tubules softly expressed galectin-3. Glomerular area was free of galectin-3 


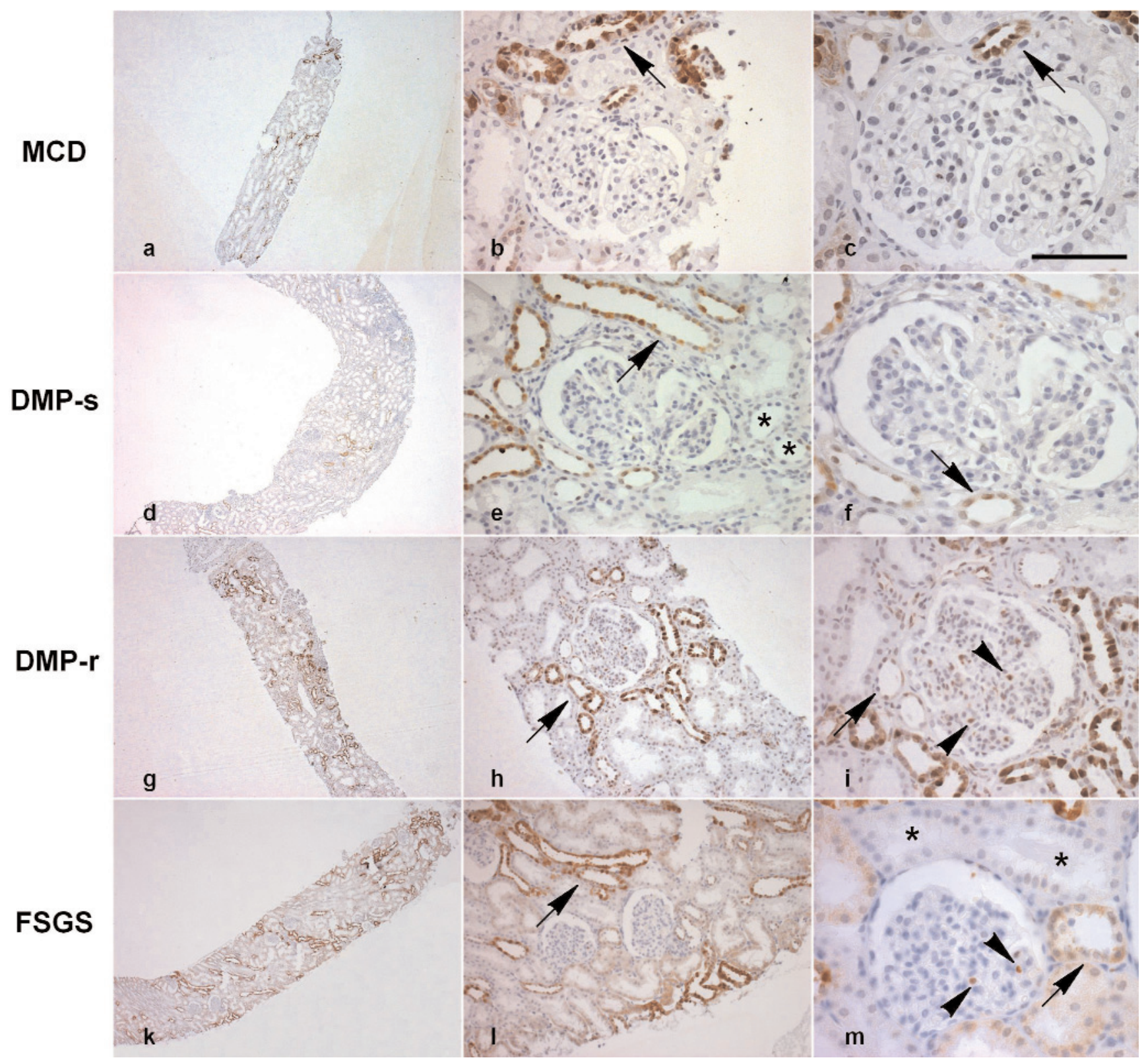

Fig. 1. Immunoreactivity for galectin-3 in renal glomeruli of children (scale bar: $800 \mu \mathrm{m}$ in a, d, g, k; $200 \mu \mathrm{m}$ in h and $1 ; 100 \mu \mathrm{m}$ in b, e, $\mathrm{i}, \mathrm{m} ; 50 \mu \mathrm{m} \mathrm{c}$ and $\mathrm{f}$ ). a-c. Nine-year-old child with minimal change disease (MCD). No galectin-3 reactivity could be found in glomerular area (c). Anti-galectin-3 reactivity is the strongest within cortical collecting ducts (arrow on b) and a subjectively slighter in distal tubules (arrow on c). d-f. Immunohistochemical expression of galectin-3 in a 5-year-old child with diffuse mesangial proliferation sensitive to steroids (DMP-s). Galectin-3 is expressed within cortical collecting ducts (arrow on e) and distal tubules (arrow on f). No galectin reactivity could be found in glomerular area (f). Notice galectin-3 negative cortical collecting ducts (asterisks on e). g-i. Glomerulus of a 7-year-old patient with diffuse mesangial proliferation resistant to steroids (DMP-r). Immunohistochemical reactivity of galectin-3 is present not only in cortical collecting ducts (arrow on $\mathbf{h}$ ) and distal tubules (arrow on i) but also within nuclei of individual mesangial cells (arrowheads on i). Notice a higher expression of immunoreactive tubules in this specimen (g) as compared to a and $\mathbf{d}$. $\mathbf{k}-\mathbf{m}$. Immunoreactivity of a galectin-3 in a 12-year-old-patient with focal segmental glomerulosclerosis (FSGS). Immunohistochemical expression of galectin-3 is present in cortical collecting ducts (arrow on l), distal tubules (arrow on $\mathbf{m}$ ) and nuclei of individual mesangial cells (arrowheads on $\mathbf{m})$. Notice a higher expression of immunoreactive tubules in this specimen (k) as compared to a and $\mathbf{d}$. The lining of proximal convoluted tubules is slightly positive (asterisks on $\mathbf{m}$ )

reactivity (Fig. 1c). On the other hand galectin-3 immunohistochemical presence was also found in both thin and thick limbs of loop of Henle and collecting ducts within renal medulla (Figs. 2a-2c). The same galectin-3 pattern was observed in all the DMP-s chil- dren. (Figs. 1d-1f). However, in subjects who did not responded to steroid therapy (both DMP-r and all the FSGS), the total number of galectin-3 positive cortical and medullar segments of collecting ducts (counted as a number of cross-sected structures per square area) 


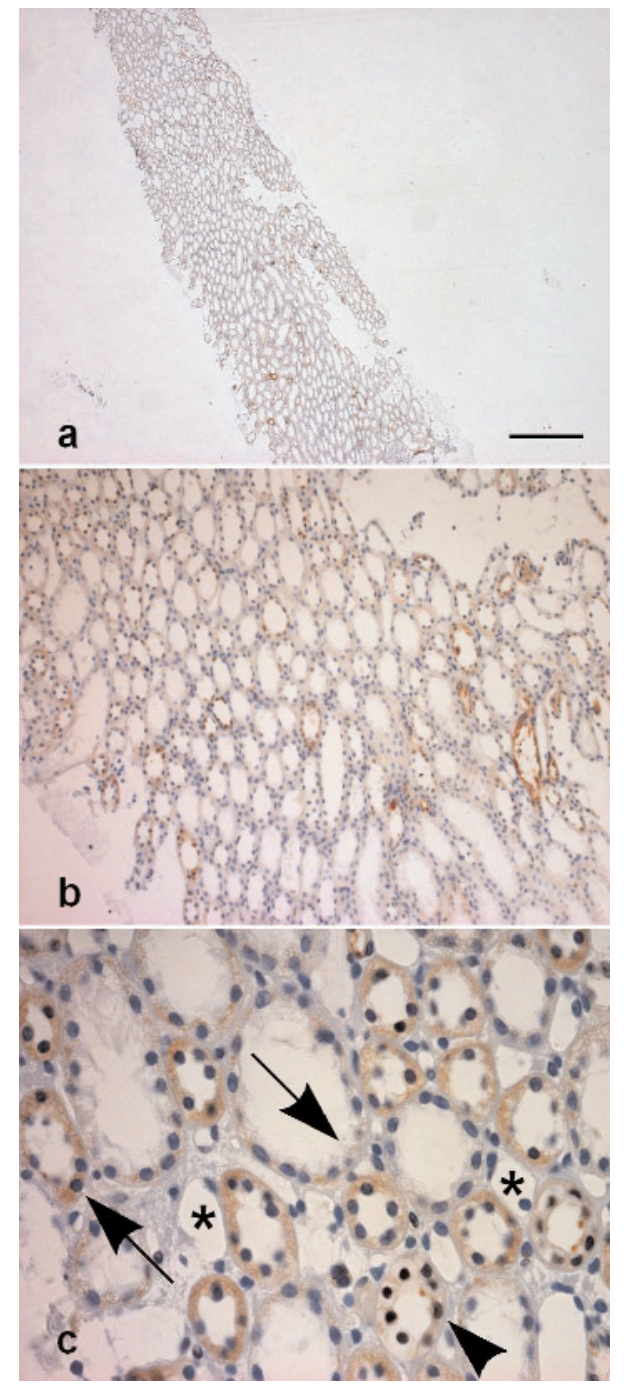

Fig. 2. Immunohistochemical expression of galectin-3 in the kidney medulla of a 7-year-old child diagnosed with DMP and steroid resistant nephrotic syndrome (scale bar $800 \mu \mathrm{m}$ in a; $200 \mu \mathrm{m}$ in b; $50 \mu \mathrm{m}$ in c). Galectin-3 immunoreactivity is present within thin and thick limbs of loop of Henle (arrows on c), medullary collecting ducts (arrowhead on c). Blood capillaries are galectin-3 negative (asterisks on $\mathbf{c}$ ).

was significantly higher $(\mathrm{p}=0.0045$; Figs. $1 \mathrm{~g}, 1 \mathrm{~h}, 1 \mathrm{k}$ and 11). Interestingly, these patients revealed also immunohistochemical reactivity of galectin-3 within nuclei of individual mesangial cells $(\mathrm{p}<0.001$, Figs. $1 \mathrm{i}$ and $1 \mathrm{~m})$. CD68 was primarily found in areas of the interstitial inflammatory infiltration (Fig. 3a) suggesting the presence of macrophages. Its localisation, however, was independent from age, sex, or type of glomerulopathy and was never followed by co-existence with galectin-3 (Figs 3a-3d).

\section{Double immunofluorescence microscopy}

In double incubations with anti-galectin-3 and antipodocalyxin the analysed markers did not reveal co- localization in renal glomeruli (Fig. 4). The expression of podocalyxin was present in podocytes of all the children. Galectin-3 was not expressed in intraglomerular structures of controls, MCD and DMP-s (data not shown). Its expression was exclusively present in the nuclei of individual cells (mesangial cells) situated in the closest proximity of glomerular capillaries of DMP-r and FSGS subjects who did not respond to steroid therapy.

\section{Discussion}

Functional properties of galectin-3 strongly suggest its importance in the regulation of the immune response and inflammation (review in [1]). In general, galectin3 is a powerful pro-inflammatory signal protein. Certain cells produce and secrete a large amount of galectin-3 as a response to various inflammatory stimuli. When secreted or externalized, galectin-3 may affect inflammatory cells by an autocrine or paracrine mechanism [review in [6]); it promotes adhesion of human neutrophils to laminin [29] as well as endothelial cells [30] and acts as a chemoattractant for monocytes and macrophages [31]. Galectins, in general, are not expressed or expressed at lower levels in resting lymphoid cells $[8,32,33]$. Infection and transformation of $\mathrm{T}$ cells with human $\mathrm{T}$ lymphotropic virus-1 or human immunodeficiency virus type 1 result in increased levels of galectin-3 [34]. Interestingly, galectin-3, which was previously known as Mac-2, could be identified on the cell surface of mouse peritoneal macrophages, and is considered as a marker for certain mature macrophages [7]. In humans, the galectin-3 level increases dramatically when monocytes differentiate into macrophages [35]. It is also expressed in mast cells [36], neutrophils [37] and eosinophils [38]. In line with this, galectin-3 is suggested to be a positive regulator of T-cell growth [39]. What is more, galectin- 3 was also documented as an anti-apoptotic factor [40,41]. It has been found to interact with a number of proteins implicated in apoptosis regulation (Bcl-2, Fas receptor) [41,42]. It appears that galectin-3 localized in the cytosol protects the cell from apoptosis, but localized in nucleus has an opposite effect (reviewed in [1]).

Results of the present report have to be discussed in two different aspects. First, as intraglomerular galectin-3 expression; secondly as its presence in extraglomerular area (both cortical and medullar).

Glomerular expression of galectin-3 was found exclusively in a few FSGS and DMP proteinuric subjects who did not respond to steroid therapy. According to the double immunofluorescence assay and the subsequent incubations with CD68, the cells reactive for galectin-3 were recognized as mesangial cells. They were not co-localised with podocalyxin - a 


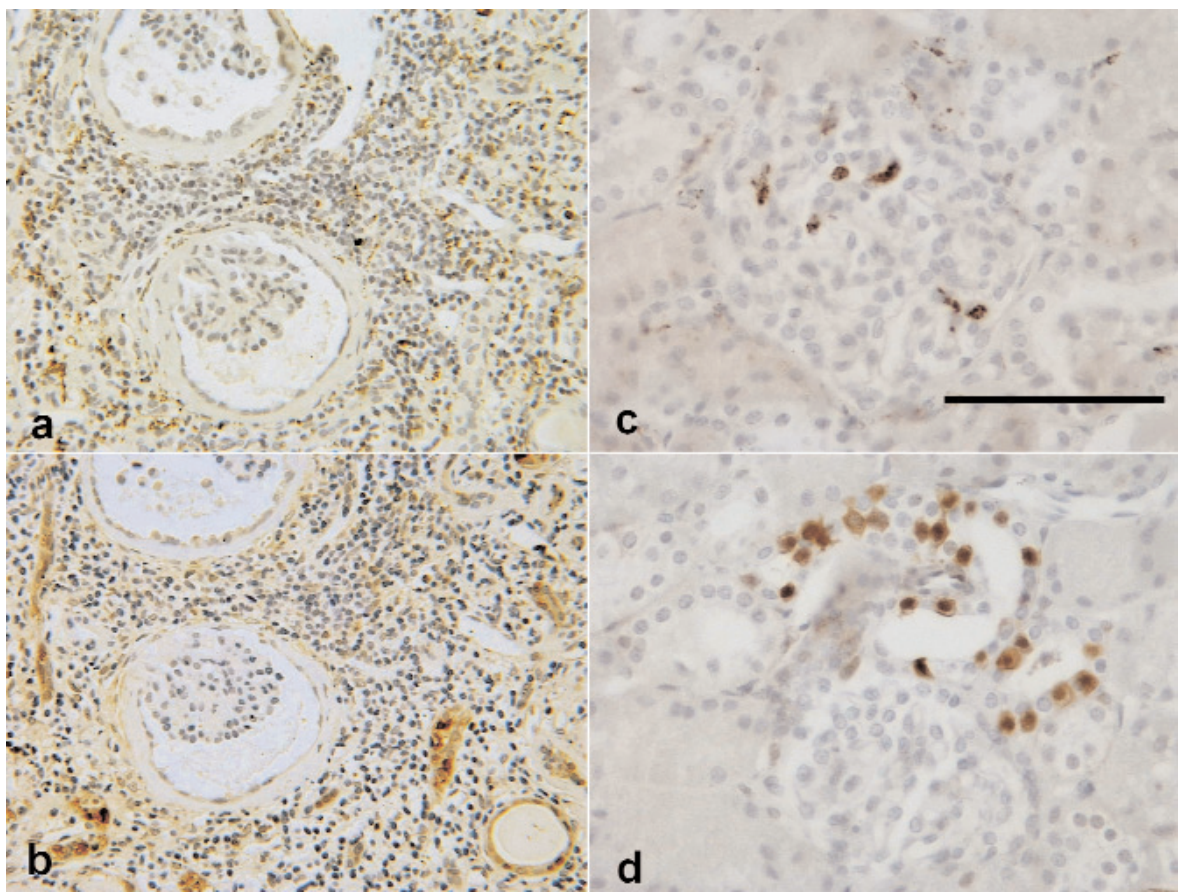

Fig. 3. Immunohistochemical expression of CD68 ( $a$ and $b$ ) and galectin-3 (c and d) in the kidney of an 8-year-old child diagnosed with DMP and steroid resistant nephrotic syndrome (scale bar $200 \mu \mathrm{m}$ in a and b; $100 \mu \mathrm{m}$ in $\mathrm{c}$ and d).CD68-positive cells (macrophages) are found primarily in areas of the interstitial inflammatory infiltration (a). They are not co-localised with galectin3 immunoreactive cells (b). Similarly, CD68-positive macrophages, if present within glomerulus (c) are not galectin-3 positive (d). marker of podocyte foot processes surface surrounding capillaries [20] and were situated outside the blood vessels. That localisation refers to another remarks of galectin-3 distribution observed in a rat model of acute mesangial proliferative glomerulonephritis [14]. Interestingly, galectin-3 positive mesangial cells in FSGS children were present exclusively within approx. $15 \%$ of glomeruli which did not reveal sclerotic features. The rest of glomeruli (85\%) was galectin-3 negative. It is in line with our another observation where four of DMP-r patients have underwent the kidney re-biopsy within 3 years of observation; all of these were diagnosed at that moment with FSGS and, curiously, had galectin-3 immuno-negative glomerular pattern.

In the study demonstrated by Kikuchi $\mathrm{Y}$ et al. the number of galectin-3-positive cells in human diabetic glomeruli significantly increased compared with other glomerular diseases [18]. In that report, most galectin-3-positive cells in all glomerular disorders were also stained with CD68 and HLA-DR, suggesting that these cells are activated macrophages [18]. It was also insinuated that infiltrated macrophages in kidneys might play an important role in the progression of IgA nephropathy, crescent glomerulonephritis and other renal diseases $[43,44]$. Moreover, the glomerular infiltration of macrophages in diabetic kidneys was thought also to play a crucial role in the progression of nephropathy. Our results indicate that both glomerular or extraglomerular galectin-3 positive cells were never co-expressed with CD68. This may suggest that, contrary to the general point of view, activated macrophages do not always need express galectin-3. Interestingly, glomerular galectin3 was expressed exclusively in the nuclei of mesangial cells suggesting its pro-apoptotic role. In our previous study involving galectin-1 expression in childhood glomerulopathies, it was detected in renal podocytes in DMP and FSGS cases, while control glomeruli and MCD were negative [20]. Galectin-1 immunoreactivity was found also within parietal epithelial cells in patients with FSGS. These results suggested a possible role for galectin- 1 in the pathogenesis of primary glomerulopathies in children as a kind of podocyte-related self-protective activity and probably involvement of epithelial cells of Bowman's capsule in inflammatory processes [20]. It seems to be possible that the similar action implied in our present report might insinuate a similar self-protective activity according to mesangial cells. On the other hand, it should result in a more favourable clinical course. Why then these patients developed resistant to steroids proteinuria?

This apparent discrepancy might not be logically explained unless we comment a second aspect of galectin-3 expression present in collecting ducts, loop of Henle and distal tubules. That localisation of galectin-3 and its possible significance in the urinary system was primarily described on animal model. It is generally believed that the expression of galectin-3 in the kidney occurs predominantly during early developmental stages $[45,46]$. The expression level in the developing mouse kidney is reduced sharply after birth, suggesting that the main role of galectin-3 is related to nephrogenesis; for example, galectin-3 functions as a negative regulator of growth and maturation 


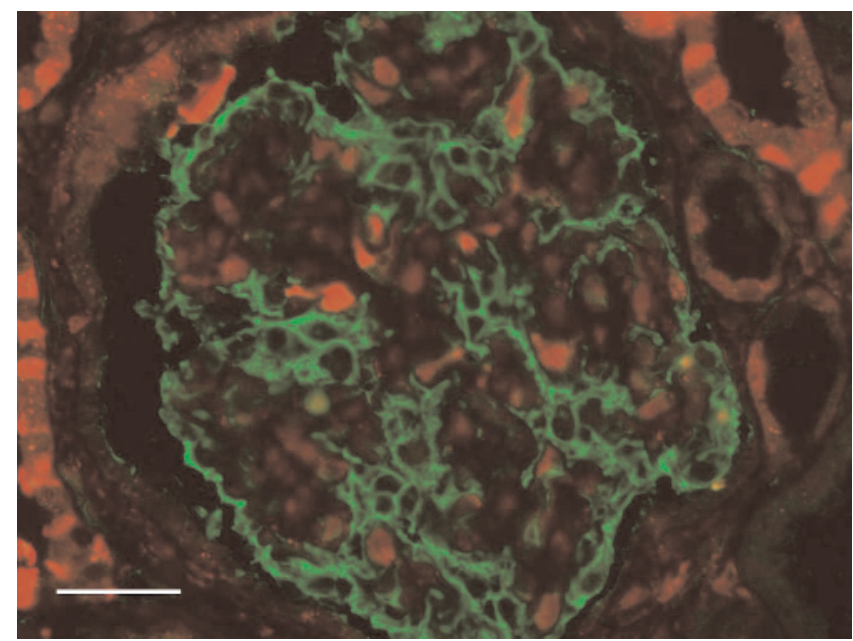

Fig. 4. Double incubation of galectin-3 (red) and podocalyxin (green) in glomerulus of a 7-year-old child with resistant to steroids diffuse mesangial proliferation (scale bar $25 \mu \mathrm{m}$ ). The expression of podocalyxin is present in podocytes (marker of podocyte foot processes surface surrounding capillaries). Galectin3 is expressed in the nuclei of individual mesangial cells situated in the closest proximity of glomerular capillaries as well as extraglomerular tubular cells.

of the uretic tree $[45,47]$ or, as described above, proapoptotic factor. Single remarks indicate also a considerably high expression level of galectin-3 in the mouse adult kidney at the mRNA and protein levels [48]. Immunohistochemically, it was predominantly expressed in the cortical collecting ducts and the connecting segments. The galectin-3 expression in the renal medulla of adult mice was less intense and was mainly localized in the medullary and papillary collecting ducts. This was in contrast to the finding in the developing human kidney, where the most intense immunoreactivity for galectin-3 was found in medullary and papillary collecting ducts rather than cortical collecting ducts [49].

In our study, a significantly higher number (density) of immunopositive tubules (loop o Henle, distal tubules and collecting ducts) was found in steroidresistant individuals (Fig. 1g and 1k). A 'tiger-like' pattern of galectin-3 immunoreactivity in cortical collecting ducts and distal convoluted tubules with its subsequent expression in cytoplasm or nuclei (Fig. 1i and $1 \mathrm{~m}$ ) we would brave to interpret as a populations of epithelial cells which are, in galecin3 dependent manner, forced into reconstruction. It then maybe followed by certain perturbation of peptides re-absorption or addition their secretion resulting in resistant to steroid but glomerularly independent proteinuria.

In line with above, a suggested galectin-3 authority in mature human glomeruli during proteinuric glomerulopathies may indicate, on the one hand, its anti-inflammatory effect, but on the other can prognosticate a further glomerular reconstruction leading to FSGS. The areas of sclerosis in FSGS and objectively decreased glomerular cellularity may explain why these structures are galectin-3 negative. Taken together, both glomerular and extraglomerular galectin-3 immunoreactivity in certain DMP individuals could be regarded as the factor of unfavourable prognosis.

Acknowledgements: The authors thank Mrs S. Bramke (from Department of Anatomy, Technical University in Dresden, Germany) for her skilful technical work. They also thank Professor Geoffrey Shaw for his assistance with the English text. The authors are indebted to Dr Aldona Wozniak for helpful discussions. This study was supported by the State Committee for Scientific Research (KBN, grant no. 0060/B/P01/2008/35).

Conflict of interest statement The corresponding (on behalf of all authors in the paper) reveals any 1) financial interests or arrangements with a company whose product was used in a study or is referred to in a manuscript, 2) any financial interests of arrangement with a competing company, 3 ) any direct payment to an author(s) from any source for the purpose of writing the manuscript, and 4) any other financial connections, direct or indirect, or other situations that might raise the question of bias in the work reported or the conclusions, implications, or opinions stated - including pertinent commercial or other sources of funding for the individual author(s) or for the associated department(s) or organization(s), personal relationships, or direct academic competition.

\section{References}

[ 1] Dumic J, Dabelic S, Floegel M. Galectin-3: an open-ended story. Biochim Biophys Acta. 2006;1760:616-635.

[2] Liu FT. Regulatory roles of galectins in the immune response. Int Arch Allergy Immunol. 2005;136:385-400.

[3] Hsu DK, Zuberi RI, Liu FT. Biochemical and biophysical characterization of human recombinant IgE-binding protein, an S-type animal lectin. J Biol Chem. 1992;267:14167-14174.

[4] Agrwal N, Sun Q, Wang SY and Wang JL. Carbohydratebinding protein 35 . I. Properties of the recombinant polypeptide and the individuality of the domains. $J$ Biol Chem. 1993;268:14932-14939.

[ 5] Mehul B, Bawumia S, Martin SR and Hughes RC. Structure of baby hamster kidney carbohydrate-binding protein CBP30, an S-type animal lectin. J Biol Chem. 1994;269:18250-18258.

[6] van den Brule F, Califice S, Castronovo V. Expression of galectins in cancer: a critical review. Glycoconj $J$. 2004; 19:537-542.

[7] Ho MK, Springer TA. Mac-2, a novel 32,000 Mr mouse macrophage subpopulation-specific antigen defined by monoclonal antibodies. J Immunol. 1982;128:1221-1228.

[ 8] Joo HG, Goedegebuure PS, Sadanaga N et al. Expression and function of galectin-3, a beta-galactoside-binding protein in activated T lymphocytes. J Leukoc Biol. 2001;69: 555-564.

[9] Yu F, Finley RL Jr, Raz A and Kim HR. Galectin-3 translocates to the perinuclear membranes and inhibits cytochrome $\mathrm{c}$ release from the mitochondria. A role for synexin in galectin3 translocation. J Biol Chem. 2002;277:15819-15827.

[10] Sharma UC, Pokharel S, van Brakel TJ et al. Galectin-3 marks activated macrophages in failure-prone hypertrophied hearts and contributes to cardiac dysfunction. Circulation. 2004;110:3121-3128. 
[11] Matarrese P, Fusco O, Tinari N et al. Galectin-3 overexpression protects from apoptosis by improving cell adhesion properties, Int J Cancer. 2000;85:545-554.

[12] Ochieng J, Green B, Evans S et al. Modulation of the biological functions of galectin-3 by matrix metalloproteinases. Biochim Biophys Acta. 1998;1379:97-106.

[13] Leffler H, Masiarz FR, Barondes SH. Soluble lactose-binding vertebrate lectins: a growing family. Biochemistry. 1989;28: 9222-9229.

[14] Sasaki S, Bao Q, Hughes RC. Galectin-3 modulates rat mesangial cell proliferation and matrix synthesis during experimental glomerulonephritis induced by anti-Thy1.1 antibodies. J Pathol. 1999;187:481-489.

[15] Nishiyama J, Kobayashi S, Ishida A et al. Up-regulation of galectin-3 in acute renal failure of the rat. Am J Pathol. 2000;157:815-823.

[16] Pugliese G, Pricci F, Leto G et al. The diabetic milieu modulates the advanced glycation end product-receptor complex in the mesangium by inducing or upregulating galectin-3 expression. Diabetes. 2000;49:1249-1257.

[17] Sedivá A, Smetana K Jr, Stejskal J et al. Binding sites for carrierimmobilized carbohydrates in the kidney: implication for the pathogenesis of Henoch-Schoenlein purpura and/or IgA nephropathy. Nephrol Dial Transplant. 1999;14:2885-2891.

[18] Kikuchi Y, Kobayashi S, Hemmi N et al. Galectin-3-positive cell infiltration in human diabetic nephropathy. Nephrol Dial Transplant. 2004;19:602-607.

[19] Saussez S, Nonclercq D, Laurent G et al. Toward functional glycomics by localization of tissue lectins: immunohistochemical galectin fingerprinting during diethylstilbestrolinduced kidney tumorigenesis in male Syrian hamster. Histochem Cell Biol. 2005;123:29-41.

[20] Ostalska-Nowicka D, Zachwieja J, Nowicki M et al. Immunohistochemical detection of galectin-1 in renal biopsy specimens of children and its possible role in proteinuric glomerulopathies. Histopathology. 2007;51:468-476.

[21] Mundel P, Shankland SJ. Podocyte biology and response to injury. J Am Soc Nephrol. 2002;13:3005-3015.

[22] Kriz W, Lemley KV. The role of the podocyte in glomerulosclerosis. Curr. Opin. Nephrol Hypertens. 1999;8:489-497.

[23] Barratt TM, Clark G. Minimal change nephritic syndrome and focal segmental glomerulosclerosis. In Holliday MA, Barratt TM, Ed A eds. Pediatric nephrology, 3rd edn. Baltimore, MD: Williams \& Wilkins, 1994;767-787.

[24] Bakker WW, van Luijk WH. Do circulating factors play a role in the pathogenesis of minimal change nephrotic syndrome? Pediatr Nephrol. 1989;3:341-349.

[25] Churg J, Habib R, White RH. Pathology of the nephrotic syndrome in children: a report for the International Study of Kidney Disease in Children. Lancet. 1970;760:1299-1302.

[26] Habib R, Girardin E, Gagnadoux MF et al. Immunopathological findings in idiopathic nephrosis: clinical significance of glomerular "immune deposits". Pediatr Nephrol. 1988;2:402-408

[27] Hsu SM, Raine L, Fanger H. Use of avidin-biotin-peroxidase complex $(\mathrm{ABC})$ in immunoperoxidase techniques: a comparison between $\mathrm{ABC}$ and unlabeled antibody (PAP) procedures. J Histochem Cytochem. 1981;29:577-580.

[28] Armitage P, Gehan EA. Statistical methods for the identification and use of prognostic factors. Int. J Cancer 1974;13:16-36.

[29] Kuwabara I, Liu FT. Galectin-3 promotes adhesion of human neutrophils to laminin. J Immunol. 1996;156:3939-3944.

[30] Sato S, Ouellet N, Pelletier I et al. Role of galectin-3 as an adhesion molecule for neutrophil extravasation during streptococcal pneumonia. J Immunol. 2002;168:1813-1822.
[31] Sano H, Hsu DK, Yu L et al. Human galectin-3 is a novel chemoattractant for monocytes and macrophages. J Immunol. 2000;165:2156-2164.

[32] Flotte TJ, Springer TA, Thorbecke GJ. Dendritic cell and macrophage staining by monoclonal antibodies in tissue sections and epidermal sheets. Am J Pathol. 1983;111:112-124.

[33] Liu FT, Albrandt K, Mendel E et al. Identification of an IgEbinding protein by molecular cloning. Proc Natl Acad Sci USA. 1985;82:4100-4104.

[34] Schroder HC, Ushijima H, Theis C et al. Expression of nuclear lectin carbohydrate-binding protein 35 in human immunodeficiency virus type 1 -infected Molt-3 cells. J. Acquir Immune Defic Syndr Human Retrovirol. 1995;9:340-348.

[35] Liu FT, Hsu DK, Zuberi RI et al. Expression and function of galectin-3, a beta-galactoside-binding lectin, in human monocytes and macrophages. Am J Pathol. 1995;147:1016-1028.

[36] Frigeri LG, Zuberi RI, Liu FT. Epsilon BP, a beta-galactosidebinding animal lectin, recognizes $\operatorname{IgE}$ receptor $(\mathrm{Fc}$ epsilon RI) and activates mast cells. Biochemistry. 1993;32: 7644-7649.

[37] Truong MJ, Gruart V, Kusnierz JP et al. Human neutrophils express immunoglobulin E (IgE)-binding proteins (Mac2/epsilon BP) of the S-type lectin family: role in IgE dependent activation. $J$ Exp Med. 1993;177:243-248.

[38] Truong MJ, Gruart V, Liu FT et al. IgE binding molecules (Mac-2/epsilon BP) expressed by human eosinophils. Implication in IgE-dependent eosinophil cytotoxicity. Eur $J$ Immunol. 1993;23:3230-3235.

[39] Yang RY, Hsu DK, Liu FT. Expression of galectin-3 modulates T-cell growth and apoptosis. Proc Natl Acad Sci USA. 1996;93:6737-6742.

[40] Yoshii T, Fukumori T, Honjo Y et al. Galectin-3 phosphorylation is required for its anti-apoptotic function and cell cycle arrest. J Biol Chem. 2002;277:6852-6857.

[41] Akahani S, Nangia-Makker P, Inohara H et al. Galectin-3: a novel antiapoptotic molecule with a functional BH1 (NWGR) domain of Bcl-2 family. Cancer Res. 1997;57:5272-5276.

[42] Fukumori T, Takenaka Y, Oka N et al. Endogenous galectin3 determines the routing of CD95 apoptotic signaling pathways. Cancer Res. 2004;64:3376-3379.

[43] Hotta O, Yusa N, Ooyama M and Taguma Y. Urinary macrophage counts and ratio to $\mathrm{T}$ lymphocytes: possible use in differential diagnosis and management of glomerular disease. J Clin Lab Anal. 1996;10:205-208.

[44] Oda T, Hotta O, Taguma Y et al. Clinicopathological significance of intratubular giant macrophages in progressive glomerulonephritis. Kidney Int. 1998;53:1190-1200.

[45] Bullock SL, Johnson TM, Bao Q et al. Galectin-3 modulates ureteric bud branching in organ culture of the developing mouse kidney. J Am Soc Nephrol. 2001;12:515-523.

[46] Hughes RC. Galectins in kidney development. Glycoconj $J$. 2004; 19:621-629.

[47] Chiu MG, Johnson TM, Woolf AS et al. Galectin-3 associates with the primary cilium and modulates cyst growth in congenital polycystic kidney disease. Am J Pathol. 2006;169:1925-1938.

[48] Nio J, Takahashi-Iwanaga H, Morimatsu M et al. Immunohistochemical and in situ hybridization analysis of galectin-3, a b-galactoside binding lectin, in the urinary system of adult mice. Histochem Cell Biol. 2006;126:45-56.

[49] Winyard PJ, Bao Q, Hughes RC and Woolf AS. Epithelial galectin-3 during human nephrogenesis and childhood cystic diseases. J Am Soc Nephrol. 1997;8:1647-1657.

Submitted: 20 November, 2008 Accepted after revision: 20 February, 2009 